\title{
DÜBLIN
}

Technological University Dublin

ARROW@TU Dublin

\section{Specification Development for Cold In-Situ Recycling of Asphalt}

\author{
Amir Tabakovic \\ Technological University Dublin, amir.tabakovic@tudublin.ie \\ Ciaran McNally \\ University College Dublin \\ Eanna Fallon \\ University College Dublin
}

Follow this and additional works at: https://arrow.tudublin.ie/resdirart

Part of the Civil and Environmental Engineering Commons

\section{Recommended Citation}

Tabaković, A.; McNally, C.; Fallon, E., 2016, "Specification development for cold in-situ recycling of asphalt", Journal of Construction and Building Materials, Vol.102, 1, pp.318 - 328. doi.org/10.1016/ j.conbuildmat.2015.10.154

This Article is brought to you for free and open access by the Directorate of Research and Enterprise at ARROW@TU Dublin. It has been accepted for inclusion in Articles by an authorized administrator of ARROW@TU Dublin. For more information, please contact arrow.admin@tudublin.ie, aisling.coyne@tudublin.ie, gerard.connolly@tudublin.ie.

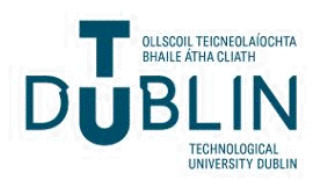


2

3

4

\section{Abstract}

6 In-situ cold recycling provides a valuable means to reduce the environmental impact of road

\author{
Amir Tabakovići ${ }^{1 *}$; Ciaran McNally²; Eanna Fallon ${ }^{2}$
}

1. Materials \& Environment, Faculty CiTG, Delft University of Technology, The Netherlands.

2. School of Civil, Structural and Environmental Engineering, University College Dublin, Ireland.

construction. The reduced energy requirements relative to traditional hot mix recycling can lead to significant reductions in cost and associated $\mathrm{CO}_{2}$ emissions. Worldwide, in-situ cold recycling has been found to be particularly useful in the rehabilitation of rural roads where site locations are far from asphalt plants. However, practical issues remain due to the evolving nature of cold bituminous materials. Unlike hot-mix asphalts which gain strength quickly as they cool, cold-mix bituminous materials gain strength slowly over time. This is particularly an issue in countries with cooler, wetter climates, such as Ireland. Consequently the specification of cold materials poses a number of challenges relating to curing and testing protocols.

This paper reports on the development of a specification for cold recycled materials and the application to a case study in Ireland. This work was conducted as part of the CEDR funded project CoRePaSol which focused on the development of harmonised design procedures for cold recycled mixes. In collaboration with the Irish National Roads Authority a $2.5 \mathrm{~km}$ site on a national road was identified for a recycling trial. The existing guidance for Low Energy Pavements was used to classify the road with respect to traffic levels and a testing programme was implemented which sought to reflect best practice across Europe. A series of recycling options were assessed and four different

\footnotetext{
*Corresponding author: a.tabakovic@tudelft.nl
} 
mix designs were proposed. These included variation in the binder type (foam mix or emulsion, with or without cement), binder content and recycling depth, reflecting the wide array of options available to engineers seeking to promote cold recycling. Due to the lack of harmonised guidelines across the Europe on design and evaluation of cold mixtures a specific focus is given in this paper to the mix evaluation procedure where alternative laboratory test specimen curing and testing procedures are investigated and recommendations are given.

Key words: Cold asphalt mix recycling, Emulsion cold mix, Foam cold mix, in-situ recycling

\section{Introduction}

\subsection{The World and EU Road Network}

The Worldwide road network consists of 16.3 million kilometres [1], and $30 \%$ of this network is the EU road network making it the largest roads network in the world [2]. These roads fulfil a major economic and social goal by facilitating the movement of goods and people throughout EU. Their operational health is of utmost importance for economic and social development of the EU. As a result, the EU governments invest heavily in an efficient transport system, with $42 \%$ (€4.5 billion) of the EU transport network fund dedicated to road networks development and maintenance [2]. The development and maintenance of this road network is very important for growth and the competitiveness of EU economy. This is particularly important for small economies within EU, such as Ireland.

Today Ireland has a road network of $96,032 \mathrm{~km}$ ( $2 \%$ of EU road network) which is approximately $24 \mathrm{~m}$ of road per capita, three times the EU average [2]. Since1995, the Irish government has invested approximately $€ 29$ billion in the development of this road network [3-5]. However since the onset of the economic recession in $2008 / 9$, national investment in new road projects has declined. Instead, the focus has moved to maintenance, with an average investment of $€ 50$ million per annum [2]. 
The ageing road infrastructure requires attention in the form of repairs and rehabilitation. Although the maintenance budget has stabilised, the number of maintenance projects are expected to increase with time. Lack of financial investment forces the development of innovative solutions and novel maintenance and rehabilitation methods. The most common method of road rehabilitation in Ireland has been complete road reinstatement, i.e. removal of the old road material and complete reconstruction of the road using new virgin materials. Recycling procedures have not been widely utilised because of the variability in the reclaimed asphalt (RA) material and due to insufficient knowledge and experience of the road recycling procedures [6]. For the past decade or so the Irish National Roads Authority (NRA), together with the road construction industry have sought to build confidence in use of RA in road [7]. One of the recycling methods being assessed is the cold recycling process [8-10].

\subsection{Cold Asphalt Recycling}

The advantage of cold asphalt recycling technology is that it allows for the recycling of existing pavements at the end of their service life [8-13]. Using recycled material compares favourably with the use of fresh aggregates in road construction as it requires less material transportation, expends less energy on material hearing and consumes less of the raw materials [11]. Despite the clear economic and environmental benefits of the cold asphalt mix technologies, doubts remain about their long term performance. If the long-term performance of cold asphalt mixes is inferior to hot mix asphalt this could negate any long-term financial or environmental benefits. The disadvantages of the cold recycling process have been well-documented and include $[8,13,14]$ : 
However, the main difficulty in the wider acceptance of the cold mix recycling is the poor of guidance available on cold mix design and evaluation processes [13], by way of standards. Across Europe, each country has adopted its own material conditioning and evaluation procedures [11]. This challenge has been addressed by the Conference of European Road Directors (CEDR) via the CoRePaSol project, which has sought to harmonize cold mix property evaluation and mix design procedures across Europe [11].

\subsection{Scope of the study}

This paper reports on the development of a specification for cold recycled materials and the application to a case study in Ireland. In collaboration with the Irish National Roads Authority a $2.5 \mathrm{~km}$ site on a national road was identified for a recycling trial. The existing National Guidance [15] for Low Energy Pavements was used to classify the road with respect to traffic levels and a testing programme was implemented which sought to reflect best practice across Europe. A series of recycling options were assessed and 4 different designs were proposed. These included variation in the binder type (foam mix or emulsion, with or without cement), binder content and recycling depth, reflecting the wide array of options available to engineers seeking to promote in-situ cold recycling as method for roads rehabilitation.

\section{Site Description and Material Characterisation}

The test site was selected by the NRA and is on a single carriageway national secondary route close to Kilkenny city, Ireland. The section was chosen because the pavement of this section of road required rehabilitation, and it is on a main commuter route with an average daily vehicle traffic count of 5,750 vehicles of which $13 \%$ are HGV. Following the NRA guidance [15], this traffic level would result in the road being characterised as Type $2 \mathrm{~b}$ road. Figure 1 illustrates a satellite image of 


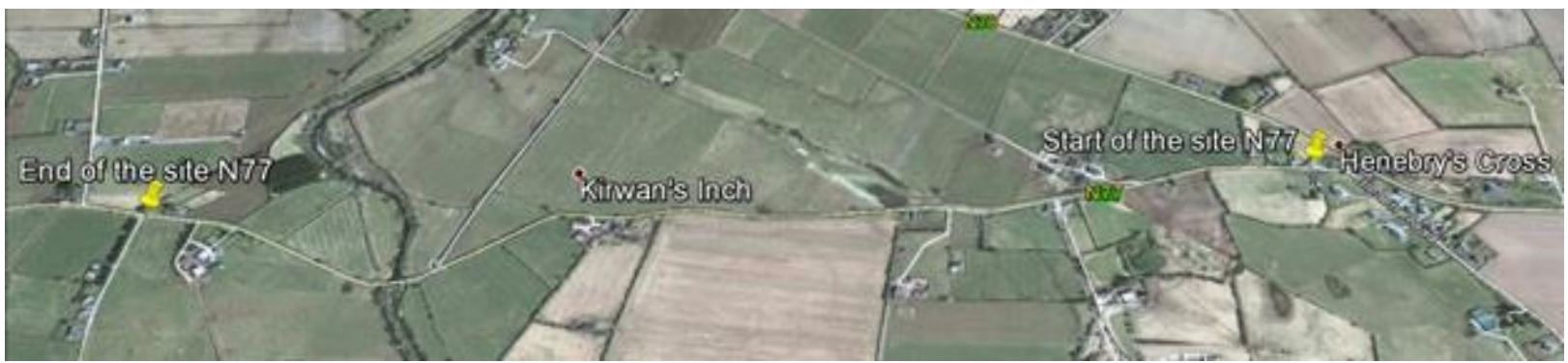

Figure 1. Satellite image of the trial road section

The initial investigation of the trial section showed a very inconsistent road structure. The images in the Figure 2 illustrate the variety of materials present throughout the length of the trial section. It can be seen that over the years there have been numerous overlays, patch repairs and surface dressings applied. This was due to the previous fragmented nature of network management in Ireland, which has resulted in a roads network with legacy issues.
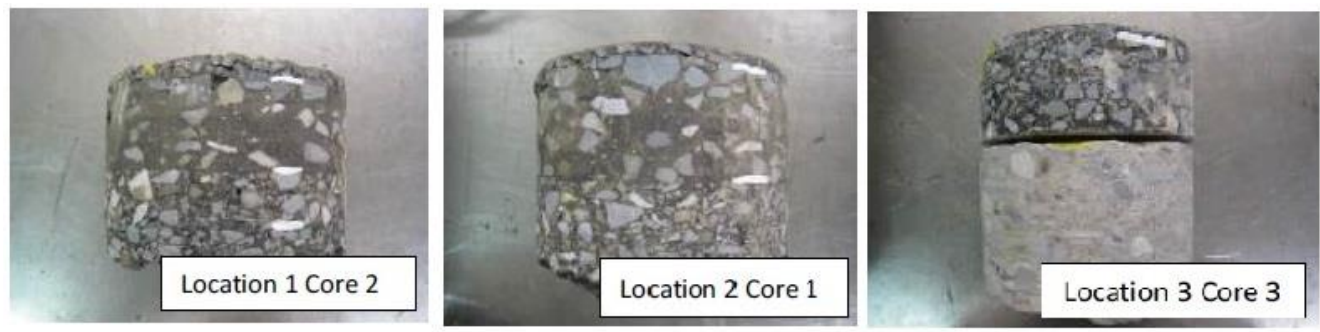

\section{Figure 2. Cores taken from existing pavement showing a large variation in material present}

Based on a ground penetrating radar survey it was decided that an appropriate recycling depth would be $300 \mathrm{~mm}$. According to the existing guidance at the time [15], recycling the existing road to the depth of $300 \mathrm{~mm}$ with surface layer of $100 \mathrm{~mm}$ is permitted for Type $2 \mathrm{~b}$ road. The road was also regularly assessed as part of the NRA's regular monitoring work and data was also available from a Falling Weight Deflectometer (FWD) survey. Using this data, the D7 deflections are presented in Figure 3. These illustrate that between length $700 \mathrm{~m}$ and $1,700 \mathrm{~m}$ the sub-base layer of the pavement is weaker and was classed as 'poor'. 
111

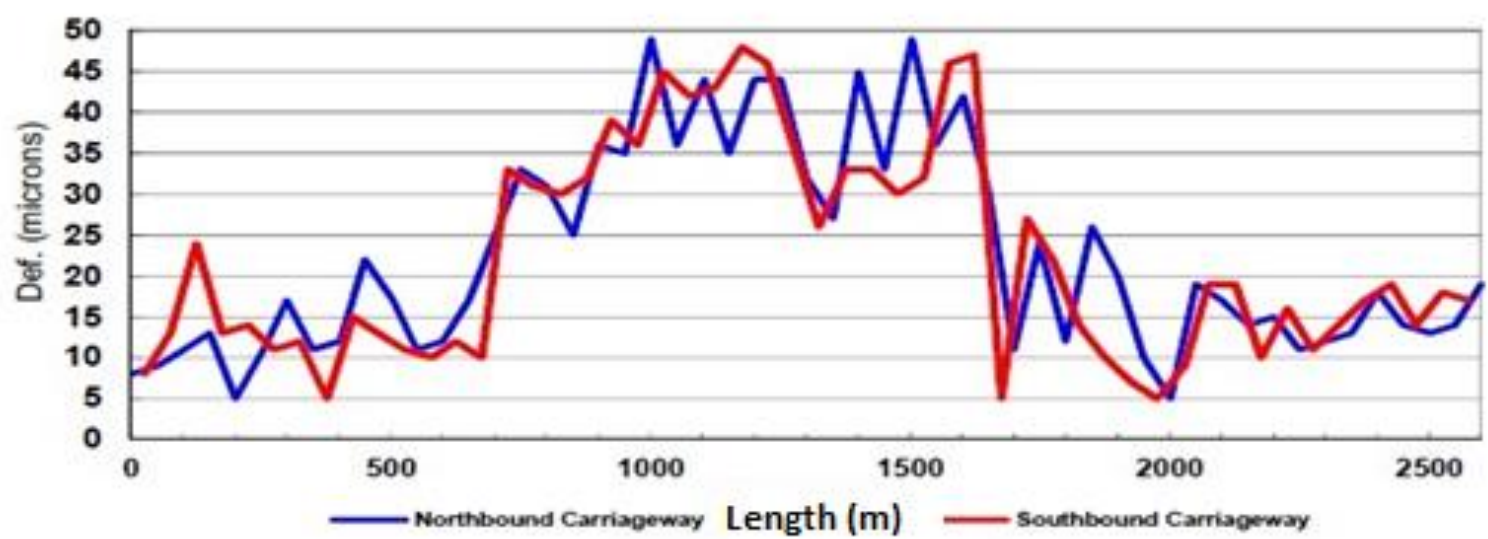

\section{Figure 3. D7 deflection data obtained from FWD survey}

These results are in agreement with anecdotal evidence that the middle zone of the site is prone to flooding during autumn and winter months. Therefore, in order to investigate the quality of the existing material the site was separated into three investigation zones and five pits were excavated. The locations of the test pits are graphically presented in Figure 4.

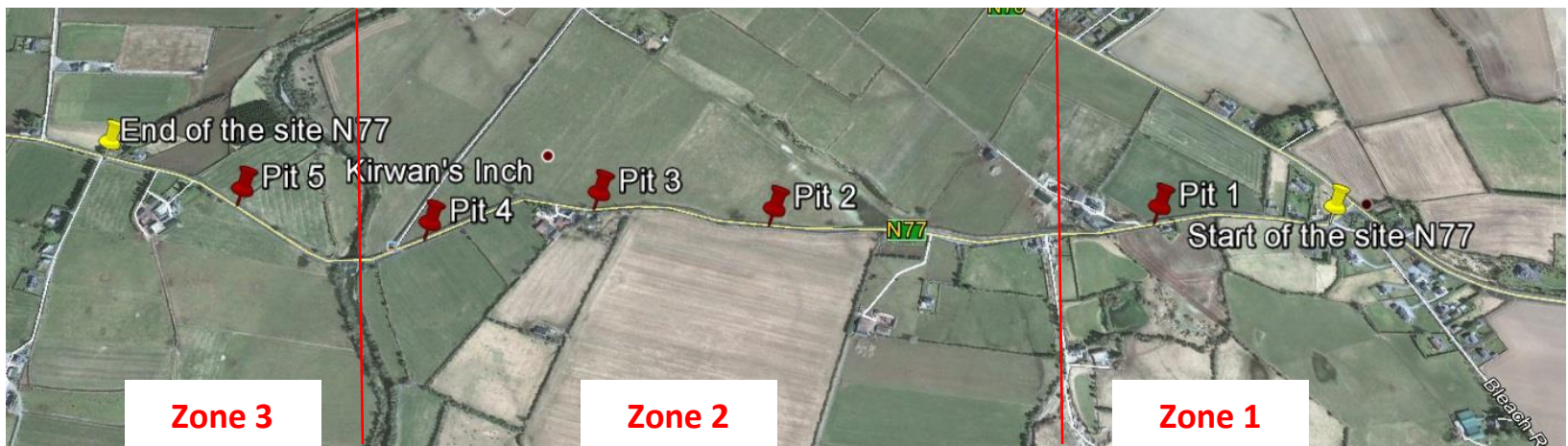

Figure 4. Satellite image of the trial road section, showing location of the test pits.

A small milling machine (with $1 \mathrm{~m}$ wide milling drum) was employed to excavate the trial pits, as shown in Figure $5 a$, to obtain material samples with a grading representative of that which would be achieved during the reconstruction process. Each trial pit was milled to $300 \mathrm{~mm}$ depth and $1000 \mathrm{~mm}$ length and width. The milling process was performed in two phases. The first phase comprised milling and removing the bituminous material only; this was to a depth of $100 \mathrm{~mm}$. In the second phase the trial pit was excavated by a further $200 \mathrm{~mm}$ and this material was also removed; this 

each pit. After the milling process was complete, CBR values were obtained for the subgrade using a Dynamic Cone Penetrometer test; the results for this are shown in Table 2. The CBR results show a stronger subgrade in pits 1 and 5 , and weaker subgrade in pits $2-4$. These results are in agreement with FWD data and suggest a weaker sub-base between $700 \mathrm{~m}$ and $1,700 \mathrm{~m}$ road length. This data supported the decision to separate the site into three investigation zones, as shown in Figure 4.

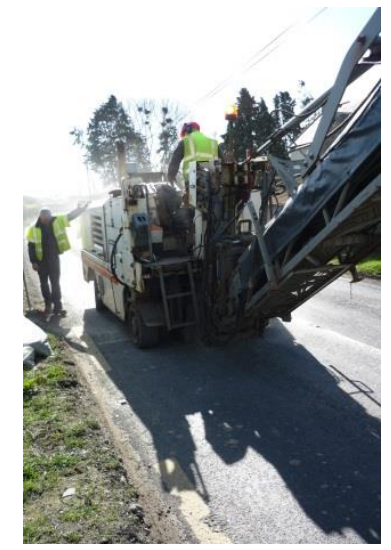

a)

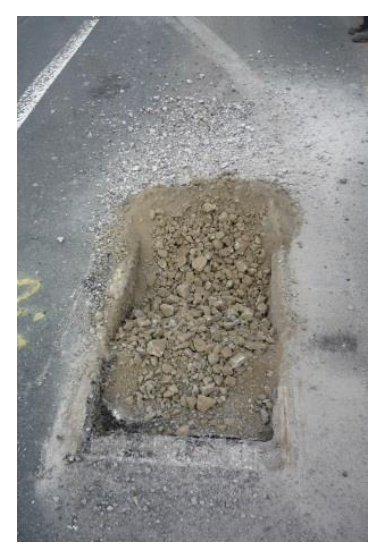

b)

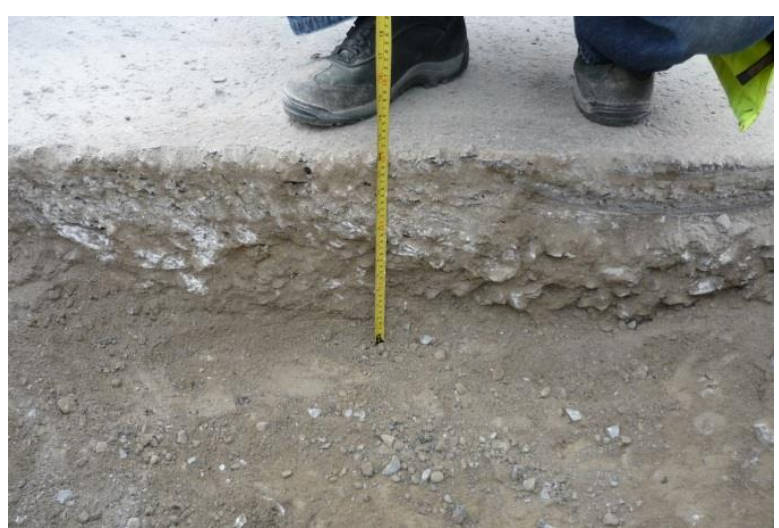

c)

132 Figure 5. Test sample pits milling, a) milling machine, b) milled granular layer and c) full depth of a 133 pit.

Table 1. CBR test results

\begin{tabular}{|l|l|l|l|}
\hline Pit No. & Layer & CBR & Comment \\
\hline 1 & 1 & 103 & \\
& 2 & 207 & Refusal \\
\hline 2 & 1 & 165 & \\
& 2 & 5 & End of ruler \\
\hline \multirow{3}{*}{3} & 1 & 104 & \\
& 2 & 21 & End of ruler \\
\hline \multirow{4}{*}{4} & 3 & 3 & \\
& 1 & 164 & \\
& 2 & 7 & End of ruler \\
\hline \multirow{5}{*}{5} & 3 & 57 & \\
& 4 & 26 & Refusal \\
\hline
\end{tabular}




\subsection{Material Characterisation}

Approximately $1000 \mathrm{~kg}$ of material was obtained from five trial pits for analysis. The material from each pit was processed separately i.e. the bituminous (surface layer) and granular materials within each batch were kept separate. On returning to the laboratory the materials were riffled and representative samples of each material were taken for moisture content and grading analysis.

\subsubsection{Material moisture level}

The moisture test results are summarised in the Table 3. The moisture tests are performed according to the BS 1377-2: 1990. The results show a low moisture level in both materials. A higher moisture level was expected in the granular layer, but this was not observed due to the material being quite coarse.

Table 2. N77 material moisture content test results.

\begin{tabular}{|l|c|c|c|c|c|}
\hline \multirow{2}{*}{ Recycled layer } & \multicolumn{5}{|c|}{ Moisture Content (\%) } \\
\cline { 2 - 5 } & Pit 1 & Pit 2 & Pit 3 & Pit 4 & Pit 5 \\
\hline Surface & 0.92 & 0.73 & 0.78 & 0.79 & 0.44 \\
\hline Granular & 1.68 & 1.98 & 1.83 & 1.41 & 1.35 \\
\hline
\end{tabular}

\subsubsection{Material grading}

The material grading is obtained according to the IS EN 933-1: 2012. The results for the grading analysis are compared to the grading limits given by the NRA guidance for recycled materials (Zone C, as per [15]) and to those in the Wirtgen cold mix manual [16]. Figure 6 shows a comparison between the NRA and Wirtgen grading envelopes. Based on the initial grading results it was found impossible to fit the material grading to the NRA grading curves without substantially changing the structure of the material, i.e. inserting fresh aggregate. On the other hand it was found that Wirtgen grading envelope is more suitable for the cold mixtures composed of recycled materials. It is considered that this difficulty with the NRA grading curve is due to the fact that the NRA guidance is also used for designing cold-mix asphalt using virgin aggregates; this is produced using an adjacent 
zone in the NRA grading curve (Zone A). The net result of this association is the development of a

158

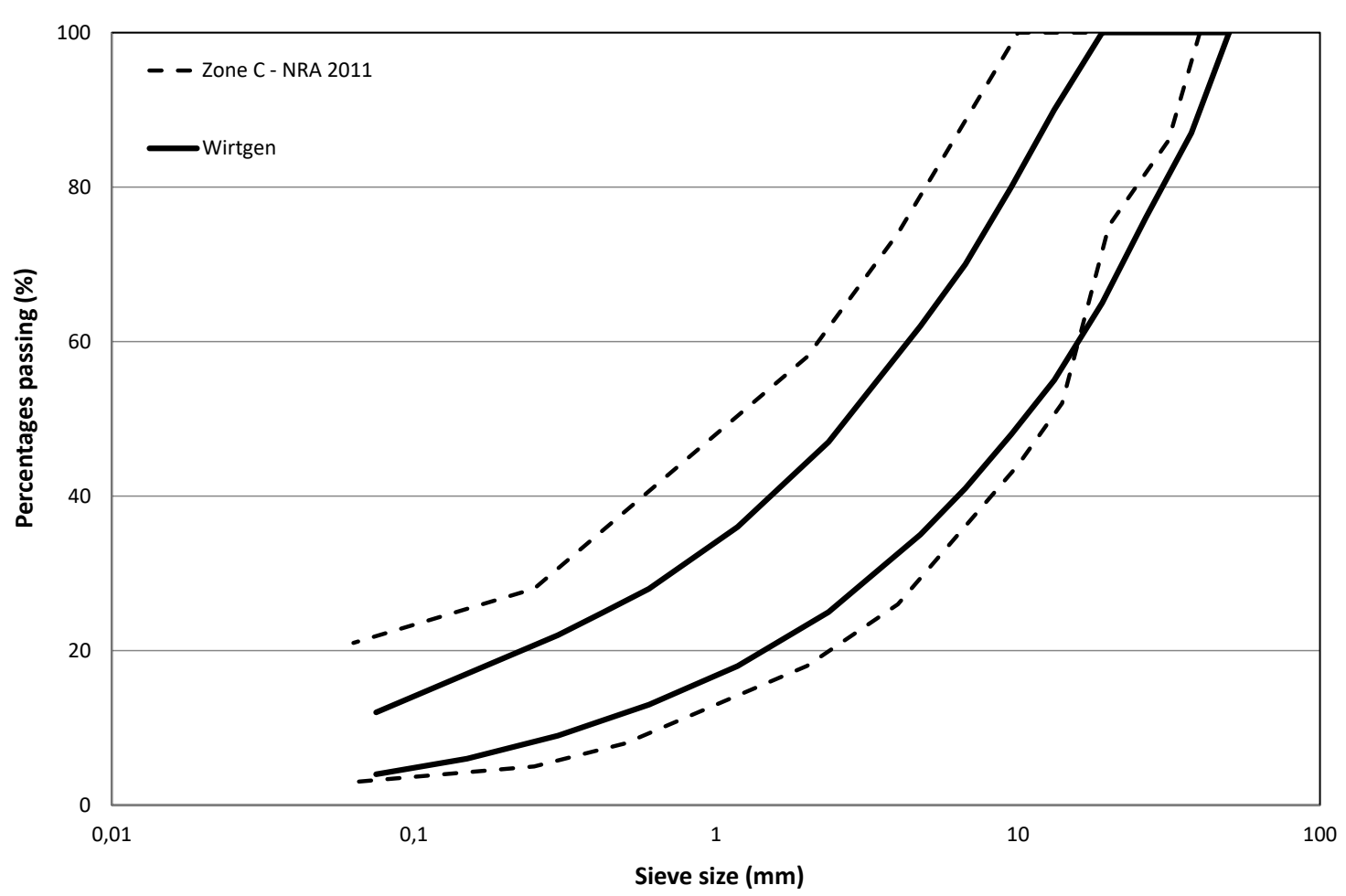

166 grading envelope for recycled materials that may not be practical or achievable. Figure 7 , shows the grading of the combined surface and granular material from each trial pit with the Wirtgen grading envelope. These gradings were created based on a recycling depth of $300 \mathrm{~mm}$ with a $100 \mathrm{~mm}$ surface layer, giving a material ratio of surface to granular of 1:2. The initial grading results showed, see Figure $7 \mathrm{a}$, that the material was lacking in fines; this was addressed by the addition of $10 \%$ crushed rock fines (CRF) for all mixes (new material grading in Figure $7 \mathrm{~b}$ ). The purpose of this was to allow the user to proceed with the mix designs; it was considered that this would not be needed in practice as a finer mix could be produced by adjusting the milling machine settings on site.

Figure 6. Cold mix grading envelopes; IRL NRA vs Wirtgen Grading Envelope. 


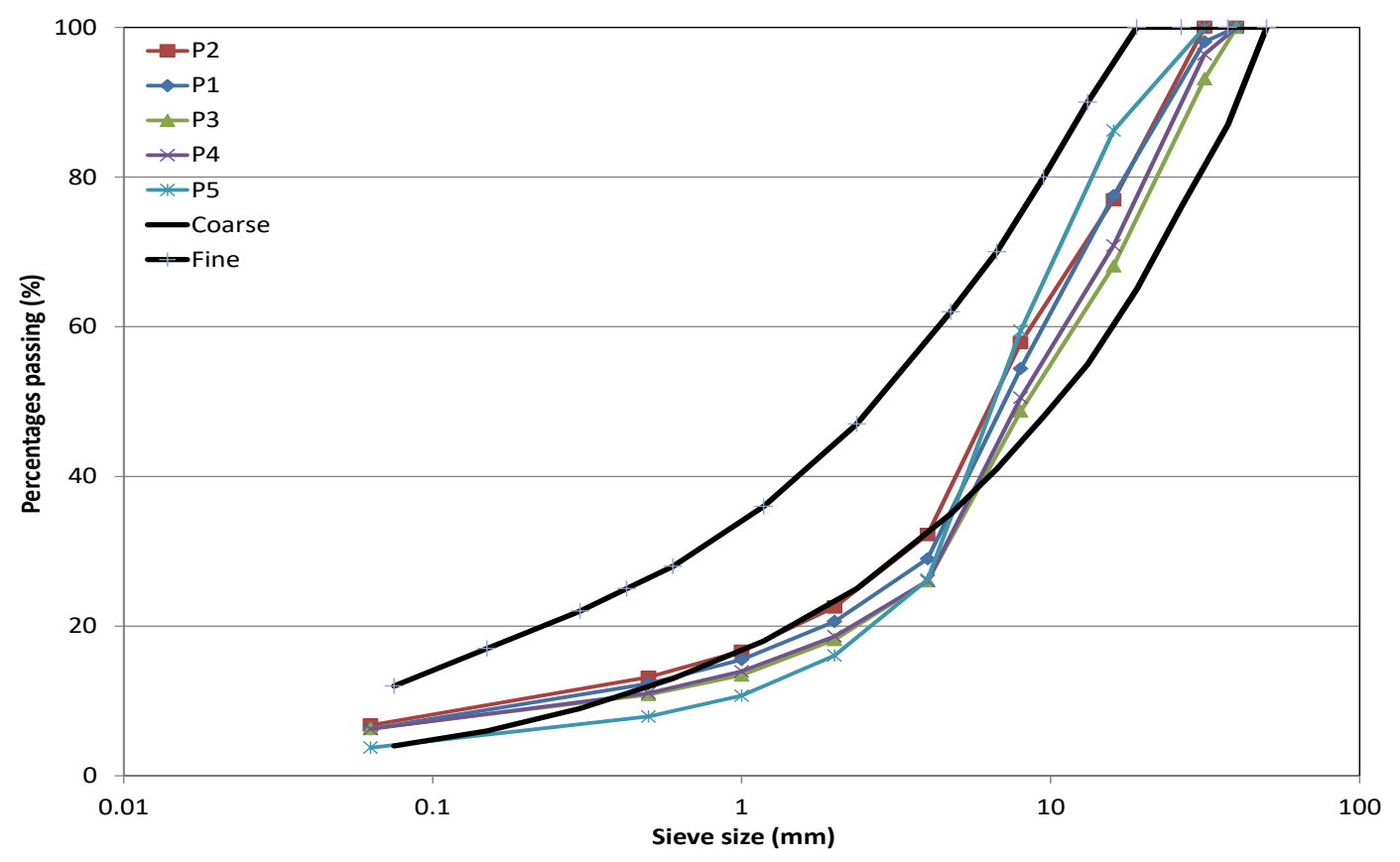

a)

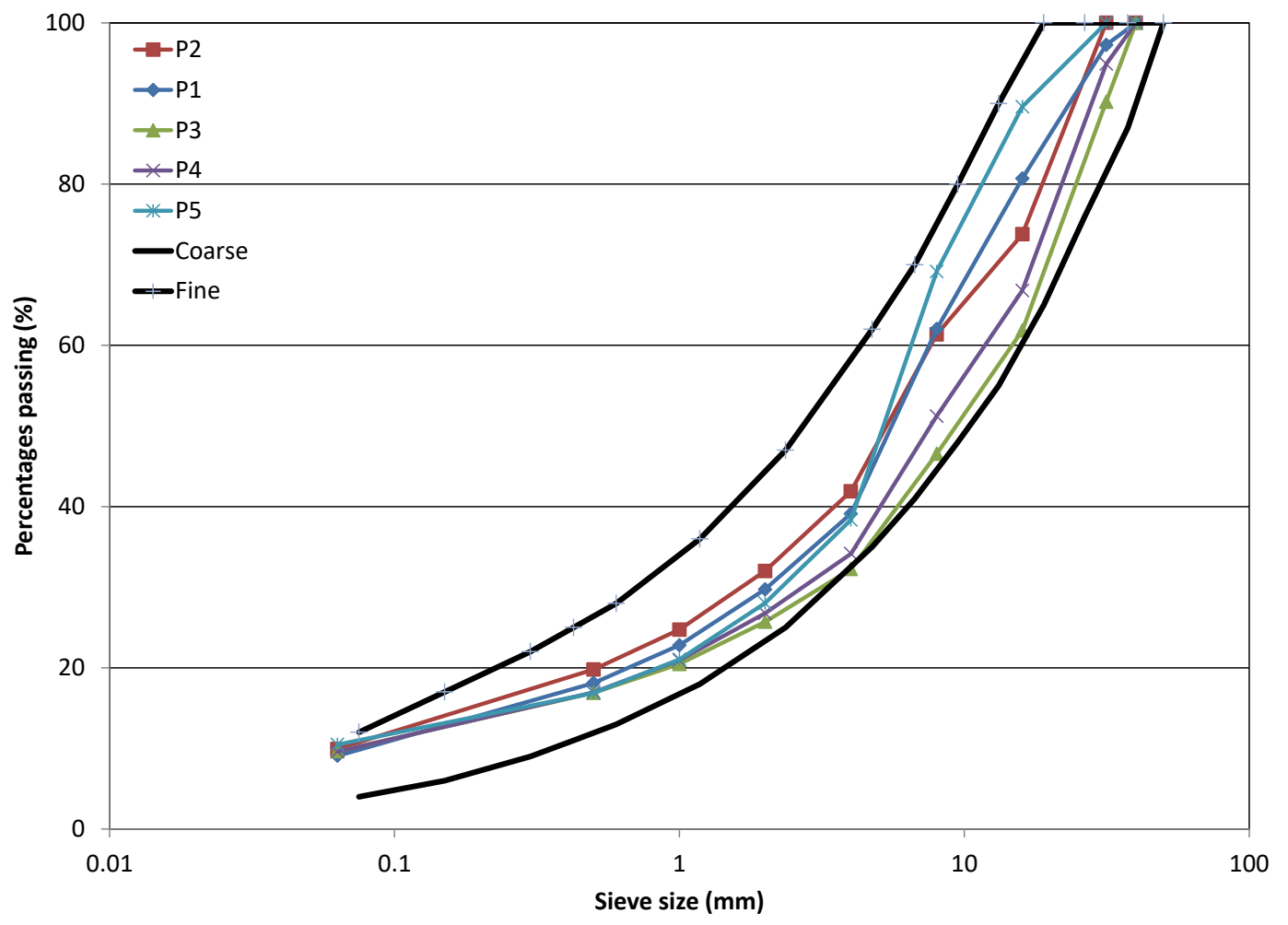

b)

Figure 7. Material mix grading: a) original material and b) material with $10 \%$ CRF. 
171 The optimum moisture content of the material was obtained using a procedure based on the 172 standard soils Proctor test, BS 1377- 4: 1990. The test results are presented in Figure 8 and show the dry density - moisture content relationship. From the graph it can be seen that there is a clear optimum moisture content for the material mix and that this is around $4 \%$. This moisture content is adopted for all material mix designs as it is just on the dry side of optimum as recommended in the NRA guidance [15].

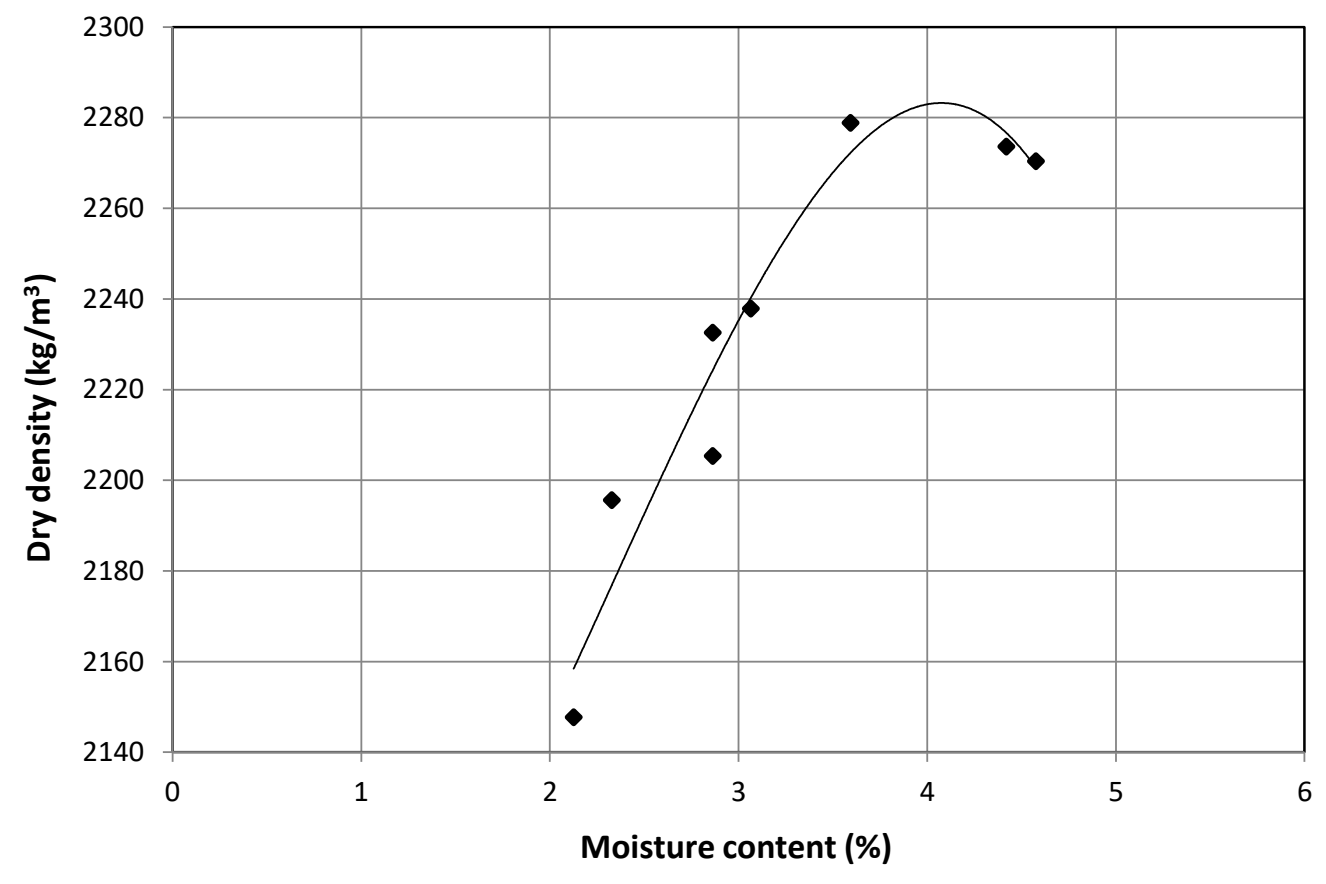

Figure 8. Dry density vs moisture content

\section{Mix Designs}

The purpose of this pavement trial is to examine performance of both emulsion and foam cold mixtures as in situ road rehabilitation processes and in turn inform the development of a new specification for cold recycled materials in Ireland. To help in this, some parameters will be set for the site trial, including:

- Mixtures used should allow for variation in cement content; 
- Differences in binder type (foamed/emulsion) should be allowed;

- Differences in binder content should be allowed.

It must also be borne in mind that the output of the FWD and GPR surveys has been to show that the existing pavement is relatively weak in the central area (designated as Zone 2 in Figure 4). Based on these considerations a series of 4 mixtures (Mix $A$ to Mix $D$ ) have been proposed and these are listed in Table 4. As previously mentioned, the site was separated into three investigation zones based on the strength of the subgrade, as shown in Figure 4 . The initial mix selection was to investigate two types of quick viscoelastic cold material mixes using:

$$
\text { i) Bitumen emulsion, }
$$

ii) Foamed bitumen.

Both mixes, designated as Mix A and Mix B, are tested with the minimum cement content of $1 \%$ [15]. Due to its weak subgrade, Zone 2 (between $700 \mathrm{~m}$ and $1700 \mathrm{~m}$ ) was designed using Mix B using foamed bitumen with $1 \%$ cement mix. This is due to the faster gain of strength associated with this material. Zones 1 (between $0 \mathrm{~m}$ and $700 \mathrm{~m}$ ) and 3 (between $1700 \mathrm{~m}$ and $2600 \mathrm{~m}$ ) were tested using an emulsion mix.

As part of the CoRePaSol project it is required to evaluate different curing procedures on the development of strength of cold recycled mixtures. Two additional emulsion mixes containing $0 \%$ and $1.5 \%$ were added to the investigation, designated as Mix $C$ and Mix $D$. These mixes are designed combining the aggregates from all five pits, i.e. they are not evaluated per individual trial pit and they do not contain CRF. The mix grading curve for these mixes is presented in the Figure 7 a and mix designs are presented in the Table 3. The emulsion/residual binder content is reduced and cement content increased in comparison to Mix A and Mix B. The rationale behind the design recipe change was that by reducing the emulsion content and slightly increasing the cement content of the mix, the emulsion cold mix performance can be improved while the mixes would also be more economical to use. This test will also be used to examine whether lower residual bitumen contents 
can be considered in the cold mix design; this would represent a significant change from the current guidance [15] where the minimum allowed residual bitumen content is $4 \%$ for in-situ production and $3 \%$ for ex-situ production where $1 \%$ cement is used in both cases.

Table 3. Mix designs.

\begin{tabular}{|l|l|c|c|c|c|c|c|}
\hline \multirow{2}{*}{$\begin{array}{l}\text { Mix } \\
\text { No. }\end{array}$} & \multirow{2}{*}{ Mix type } & \multicolumn{7}{|c|}{ Mix Constituents (\%) } \\
\cline { 3 - 8 } & $\begin{array}{c}\text { Surface } \\
\text { Material }\end{array}$ & $\begin{array}{c}\text { Granular } \\
\text { Material }\end{array}$ & CRF & Cement & Water & $\begin{array}{c}\text { Residual } \\
\text { Binder }\end{array}$ \\
\hline A & Emulsion & 27.4 & 55.3 & 10 & 1.0 & 4.0 & 3.0 \\
\hline B & $\begin{array}{l}\text { Foamed } \\
\text { Bitumen }\end{array}$ & 27.4 & 55.3 & 10 & 1.0 & 4.0 & 3.0 \\
\hline C & Emulsion & 31.2 & 62.6 & 0 & 0.0 & 4.0 & 2.2 \\
\hline D & Emulsion & 30.8 & 61.6 & 0 & 1.5 & 4.0 & 2.2 \\
\hline
\end{tabular}

\section{Testing and Results}

\subsection{Compaction}

Following previous work by Hogan et al. [8] and Doyle et al. [17]), the gyratory compaction procedure was adopted for this study. All of the specimens were compacted in accordance with IS EN 12697-31:2007 using a Coopers Technology gyratory compactor. The static compaction pressure was set at $0.6 \mathrm{MPa}$ with an angular velocity of 30 gyrations per minute and the gyratory angle set at gyrations. For this study the cylindrical test specimens are compacted to target dimensions of $150 \mathrm{~mm}$ in diameter and $75 \mathrm{~mm}$ in height. Slotted moulds are used to allow for drainage of the excess moisture and thus better compaction. The same weight of material $(3.0 \mathrm{~kg})$ is placed into the mould for all specimens. After compaction, test specimens are left in the mould to cure for 24 hours. The test specimens are then extruded, and their dimensions and weight recorded. The specimens are then ready for curing. 
In order to assess the performance of the gyratory compaction as a method, maximum density tests were performed on Mix C and Mix D in accordance to the EN 12697 - 5: 2009. The results also suggest that cement content in the mix does not affect air void content. These findings are contractictory to the findings found in the literature [18] where reduction in the mix air voids is related to the increase in the cement in the mix. However, results show that air voids decrease with increase of the moisture content, which confirms the conclusion that cement content does not affect the air voids content in the mix but the moisture content in the mix. Table 4 summarises the results of the moisture content after curing, densities and void content in these specimens. A low moisture content was observed for all mixes and those containing cement do not show lower moisture content after the specified conditioning period. The air voids content is lower than expected (4\%), although this may occur when working to a specified level of compaction (100 gyrations). The results also suggest that cement content in the mix does not affect air void content. These findings are contradictory to the findings found in the literature [18] where reduction in the mix air voids is related to the increase of cement in the mix. However, results show that air voids decrease with increase of the moisture content, which confirms the conclusion that cement content does not affect the air voids content in the mix but the moisture content in the mix.

Table 4. Max and Bulk densities and air voids content of test specimens compacted in lab.

\begin{tabular}{|c|c|c|c|c|c|c|}
\hline $\begin{array}{l}\text { Mix } \\
\text { No. }\end{array}$ & Mix type & Curing Method & $\begin{array}{c}\text { Moisture } \\
\text { Content (\%) }\end{array}$ & $\begin{array}{c}\text { Max Density } \\
\left(\mathrm{kg} / \mathrm{m}^{3}\right)\end{array}$ & $\begin{array}{c}\text { Bulk Density } \\
\left(\mathrm{kg} / \mathrm{m}^{3}\right)\end{array}$ & $\begin{array}{c}\text { Air voids } \\
(\%)\end{array}$ \\
\hline \multirow{2}{*}{ C } & \multirow{2}{*}{$\begin{array}{l}\text { Emulsion mix, } \\
0 \% \text { cement }\end{array}$} & 7 days at $20^{\circ} \mathrm{C}$ & 1.6 & 2,351 & 2,279 & 3.1 \\
\hline & & 14 days at $20^{\circ} \mathrm{C}$ & 1.0 & 2,287 & 2,210 & 3.4 \\
\hline \multirow{2}{*}{ D } & \multirow{2}{*}{$\begin{array}{l}\text { Emulsion mix, } \\
1.5 \% \text { cement }\end{array}$} & 7 days at $20^{\circ} \mathrm{C}$ & 1.4 & 2,291 & 2,204 & 3.8 \\
\hline & & 14 days at $20^{\circ} \mathrm{C}$ & 1.5 & 2,343 & 2,279 & 2.8 \\
\hline
\end{tabular}

Various curing temperatures, durations and methods are used for cold mix materials around the world $[13,15,17-23]$. Cold mix materials with bitumen emulsion develop their strength over a period of time [14]. It is therefore necessary to speed up this curing process to obtain an early 
indication of long-term strength [14]. The NRA guidance [15] has put forward a curing temperature of $40^{\circ} \mathrm{C}$ for duration of 28 days for cold recycled asphalt materials. However, this procedure has been criticised by industry due its impracticality [8]. This curing procedure is too prolonged for an insitu cold recycling project as the project deadline may be passed before the laboratory results and appropriate designs are available. This serves to make cold recycling techniques unpopular as a standard practice for road rehabilitation projects.

When assessing alternative curing methodologies, a number of options are considered. The first set of the test specimens (Mixes A \& B) are cured according to the current accelerated curing procedure described in the NRA guidance [15]. This involves sealing the specimens in a plastic bag and placing them in an oven for 28 days at $40^{\circ} \mathrm{C}$. This is intended to represent the long-term properties of the mix after one year.

The second set of specimens (Mixes C \& D) were cured according to the methods used in Portugal, the Czech Republic and Germany. The specimens without cement (Mix C) are cured unsealed for 3 days at $50^{\circ} \mathrm{C}$ as per Portuguese and Spanish practice $[24,25]$. The specimens containing cement are cured for 14 days at $20^{\circ} \mathrm{C}$ as per the Czech Republic and German standard [11]. This slower curing regime for mixtures containing cement is necessary as hydraulic binders (e.g. cement and lime) can hydrate too quickly at higher temperatures, resulting in specimen cracking and unreliable assessment.

\subsection{Testing}

Standard asphalt testing procedures such as ITSM and ITS have been reported to be suitable for an evaluation of cold mix asphalt performance $[8,13,14,17-21,26,27]$. In order to evaluate the mechanical performance of the cold recycled materials, two tests were employed:

1. Indirect Tensile Stiffness Modulus Test (ITSM).

2. Indirect Tensile Strength Tests (ITS). 
The non-destructive ITSM test is conducted which complied with IS EN 12697-26: 2012. The Cooper Research Technology NU-10 testing apparatus with a pneumatic close loop control system is used. After the completion of the prescribed curing process, test specimens are removed from the sealed plastic bags and their dimensions and weights are re-recorded. They are then placed in a temperature controlled chamber at $20^{\circ} \mathrm{C}$ for three hours prior to testing. The stiffness value is recorded on two diameters orientated at $90^{\circ}$ to each other, and an average of these two values is reported as the specimen stiffness.

\subsubsection{Indirect tensile strength (ITS) test}

On completion of the curing process, the specimens were stored in a temperature control chamber at $20^{\circ} \mathrm{C}$. The test specimens are then conditioned at a test temperature of $25^{\circ} \mathrm{C}$ for three hours prior to testing. A Controls testing system is employed to complete the Indirect Tensile Strength Test (ITS) in accordance with IS EN 12697-23: 2003. The ITS test is conducted by applying a vertical compressive strip load to a cylindrical specimen. The load is distributed over the thickness of the specimen through two loading strips at the top and bottom of the test specimen.

Table 5. Laboratory mixes - ITSM test results

\begin{tabular}{|c|c|c|c|c|c|}
\hline Mix No. & Trial Pit No. & Mix type & Curing Method & $\begin{array}{l}\text { ITSM } \\
\text { (MPa) }\end{array}$ & $\begin{array}{l}\text { ITS dry } \\
\text { (MPa) }\end{array}$ \\
\hline \multirow{2}{*}{ A } & 1 & \multirow{2}{*}{ Emulsion mix (1\% cement) } & \multirow{2}{*}{28 days at $40^{\circ} \mathrm{C}$} & 2978 & 0.43 \\
\hline & 5 & & & 2364 & 0.43 \\
\hline \multirow{3}{*}{ B } & 2 & \multirow{3}{*}{ Foam mix ( $1 \%$ cement) } & \multirow{3}{*}{28 days at $40^{\circ} \mathrm{C}$} & 5503 & 0.57 \\
\hline & 3 & & & 4738 & 0.53 \\
\hline & 4 & & & 4824 & 0.56 \\
\hline C & Combined & Emulsion mix (0\% cement) & 3 days at $50^{\circ} \mathrm{C}$ & 2254 & 0.35 \\
\hline $\mathrm{D}$ & Combined & Emulsion mix (1.5\% cement) & 14 days at $20^{\circ} \mathrm{C}$ & 3526 & 0.41 \\
\hline
\end{tabular}


The results of the ITSM test on all mixes, along with the respective curing method used, are

295 presented in Table 5. For the case of Mix A, the samples produced using material from both trial pits 1 and 5 showed a good level of performance and a long term ITSM value in excess of 2000 MPa and a consistent indirect tensile strength of $0.43 \mathrm{MPa}$.

The foamed bitumen material (Mix B) was produced using material from trial pits 2, 3 and 4 . The ITSM values for these mixes were higher than expected with an average value at $5022 \mathrm{MPa}$. This may raise some concern as to whether the material would have sufficient flexibility to accommodate a poor subgrade without cracking prematurely. However, Tabakovic et al. [6] reported that the stiffness value for the hot binder course mix containing 30\% RA at 3.5\% binder content is in range of 5100MPa. Which indicates that Mix B has achieved full stiffness value. The indirect tensile strength was quite consistent, with an average value of $0.55 \mathrm{MPa}$.

The emulsion material containing no cement (Mix $C$ ) was manufactured using a blend of material combined from all 5 trial pits, and yielded an ITSM value in excess of $2000 \mathrm{MPa}$. While this is in good agreement with the results achieved for Mix A, it should be noted that this curing temperature is not representative of environmental conditions in Northern Europe; it is also not suitable for cement containing mixtures. The indirect tensile strength was also quite low, returning a value of $0.35 \mathrm{MPa}$.

Finally, Mix D was also produced using material combined from all 5 trial pits and cured for 14 days at $20^{\circ} \mathrm{C}$. The ITSM value was also quite high, yielding a result of over $3500 \mathrm{MPa}$. The indirect tensile strength was slightly lower than expected, producing a value of $0.41 \mathrm{MPa}$.

It is worth noting that emulsion mixtures, have shown low stiffness values (between $2254-3526$ $\mathrm{MPa}$ ) in comparison to the foam mix and equivalent hot recycled binder course mix containing $30 \%$ RA, which stiffness is in range of 5000MPa. However, as reported by Doyle et. al. [14] and AlBusaltan et. al. [19] it is believed that stiffness and strength gain will increase in time. This cold mix behaviour will be investigated on site where regular FWD test will be carried on. It is expected that emulsion mixtures will reach full strength within 12 months of its service life. 
These results showed that all four mixes met the minimum ITSM requirement for use on site, and suggested that Mix B would be the most suitable for the section of the site with the weakest subgrade due to its high stiffness and tensile strength.

Mixes $A$ and $B$ have performed very well with a residual binder content of $3 \%$ and $1 \%$ cement. However, Mix D used a lower residual binder content of $2.2 \%$ with $1.5 \%$ cement and outperformed Mixes $A$ and $B$. these results show that lower residual bitumen contents can be considered for in-situ production than currently allowed.

\section{In-Situ Cold Recycling Site Trial}

A key aim of this study is to validate the proposed specification against a full-scale site trial. Each of the four mixes designed in the previous sections were to be used in the construction; the location is shown in the schematic layout presented in Figure 9. It can be seen that Mix B, which produced the highest stiffness and indirect tensile strength was used in Zone 2 - the section with the weakest subgrade. Mix C, which produced the lowest stiffness and ITS was used in the section with the strongest subgrade.

The recycling depth used for sections 1, 2 and 3 (Zone 1 \& 2, see Figure 4) was 300mm while the depth used for sections 4 and 5 (Zone 3, see Figure 4 ) was $250 \mathrm{~mm}$. Due to the nature of the Irish climate, it is not permitted to use cold recycled materials in a pavement surface layer. Furthermore, this would not be feasible due to the high trafficking levels on this particular road. For this particular project the cold recycled material was overlain with:

- A 55mm thick layer of $6 \mathrm{~mm}$ SMA regulation course (for Zones 1 and 3);

- A $55 \mathrm{~mm}$ thick layer of $20 \mathrm{~mm}$ dense asphalt concrete (for Zone 2);

- A 40mm surface layer of hot rolled asphalt (HRA 30/14 F Surf 40/60 rec; all Sections). 


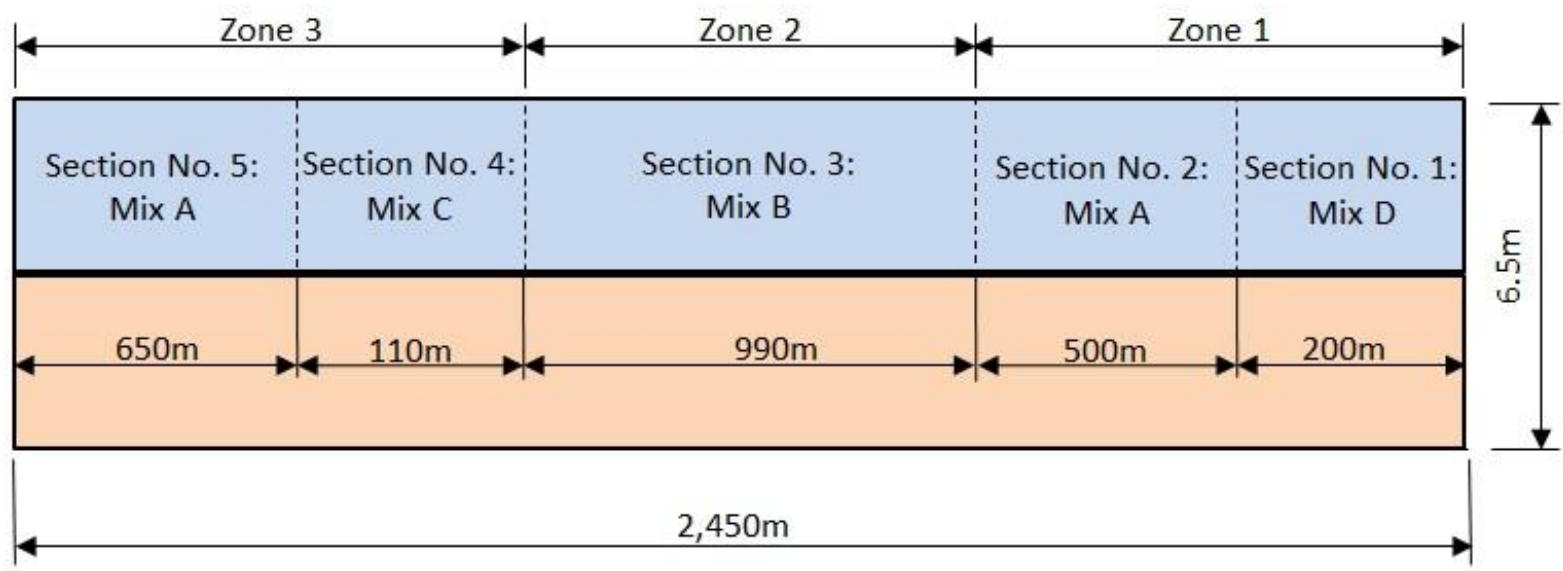

Figure 9. Revised schematic representation of the trail section

\subsection{Validation of Mix Design}

As described in Section 3, mix designs were developed in the laboratory for materials taken directly from trial pits on site. This process was followed up with testing of materials obtained from actual job site. This presents some very practical challenges as the very nature of cold recycled materials means that they gain strength with time. In this case, the distance between the site location and the research laboratory is $100 \mathrm{~km}$. Furthermore, three of the four mixes contained cement which required that the in-situ produced materials be sampled and compacted on the same day. Each of the five sections within the site trail was sampled. The material collection and transport procedure was as follows:

1. Approximately $20 \mathrm{~kg}$ of the material was taken from behind the recycling machine and placed into a plastic bag; this bag is then sealed and marked. Four sample bags were collected for each material, providing a total of $80 \mathrm{~kg}$ for each material mix.

2. The plastic bag containing the material sample was placed within a sealed plastic container. Great care was taken to ensure that moisture from the mix did not evaporate prior to the compaction process. 


\subsubsection{Specimen preparation}

359

360

361

362

363

364

365

366

367

368

369

The specimens are compacted three hours after the in-situ mix production. Thanaya et al. [13] have previously shown the importance of compacting cold emulsion test specimens within six hours of mix production. They have found that any delay in compaction allows the cement to hydrate in the loose mixture. This is represented by a reduction in bond between the mineral aggregate particles and ultimately a lower ITSM value. To overcome this, the material is remixed and riffled upon arrival at the testing laboratory. The specimens are then compacted using the gyratory compactor as described in Section 4.1. They are then extruded and cured as described in section 4.2 On completion of the curing process, the specimens are tested using the ITSM and ITS test as previously described in Section 4.3.1 and 4.3.2.

\subsection{In-Situ Material Test Results}

The results from the ITSM and ITS tests for the in-situ site material are presented in Table 6, alongside the comparative result from the laboratory produced material. The results show that Mixes $A, B$ and $D$, which contain cement, have achieved the minimum stiffness requirement for 1year of $2000 \mathrm{MPa}$ [15]. Mix D which had a reduced binder content of $2.2 \%$ and a $1.5 \%$ cement content had a stiffness in excess of $2000 \mathrm{MPa}$ and has an ITS value of $0.37 \mathrm{MPa}$. Mix B had a high ITSM value (over $4400 \mathrm{MPa}$ ) and a high ITS value, confirming that it is best suited for use in the section with the lowest strength subgrade. It is however notable that Mix C (reduced binder content, no cement) did not meet the $2000 \mathrm{MPa}$ minimum requirement and also had the lowest ITS. This material was however used in the section with the highest strength subgrade. 


\begin{tabular}{|c|c|c|c|c|c|c|c|c|}
\hline \multirow[b]{2}{*}{$\begin{array}{c}\text { Zone } \\
\text { No }\end{array}$} & \multirow[b]{2}{*}{$\begin{array}{c}\text { Section } \\
\text { No. }\end{array}$} & \multirow[b]{2}{*}{$\begin{array}{l}\text { Mix } \\
\text { No. }\end{array}$} & \multirow[b]{2}{*}{ Mix type } & \multirow[b]{2}{*}{$\begin{array}{c}\text { Curing } \\
\text { programme }\end{array}$} & \multicolumn{2}{|c|}{ ITSM } & \multicolumn{2}{|c|}{ ITS dry } \\
\hline & & & & & $\begin{array}{l}\text { In-situ } \\
\text { Mixed } \\
\text { Material } \\
\text { (MPa) }\end{array}$ & $\begin{array}{l}\text { Relative to } \\
\text { Lab Mixed } \\
\text { Material } \\
\text { (\%) }\end{array}$ & $\begin{array}{l}\text { In-situ } \\
\text { Mixed } \\
\text { Material } \\
(\mathrm{MPa})\end{array}$ & $\begin{array}{l}\text { Relative to } \\
\text { Lab Mixed } \\
\text { Material(\%) }\end{array}$ \\
\hline \multirow{2}{*}{1} & 1 & $\mathrm{D}$ & Emulsion mix (1.5\% cement) & 14 days, $20^{\circ} \mathrm{C}$ & 2283 & 65 & 0.37 & 90 \\
\hline & 2 & A & Emulsion mix (1\% cement) & 28 days, $40^{\circ} \mathrm{C}$ & 2959 & 99 & 0.43 & 100 \\
\hline 2 & 3 & B & Foam mix (1\% cement) & 28 days, $40^{\circ} \mathrm{C}$ & 4409 & 88 & 0.48 & 87 \\
\hline \multirow{2}{*}{3} & 4 & C & Emulsion mix ( $0 \%$ cement) & 3 days, $50^{\circ} \mathrm{C}$ & 1128 & 50 & 0.32 & 91 \\
\hline & 5 & A & Emulsion mix (1\% cement) & 28 days, $40^{\circ} \mathrm{C}$ & 4,495 & 190 & 0.68 & 158 \\
\hline
\end{tabular}

384 When one compares the performance of the site mixed materials relative to the lab mixed materials,

385 there are some interesting comments that may be made. The use of site mixed materials from

386 Section 5 for Mix A produced surprisingly high ITSM and ITS values (4495 MPa and $0.68 \mathrm{MPa}$

387 respectively). When the same design was used with material arising from Section 2, the values

388 produced were significantly lower (ITSM of $2959 \mathrm{MPa}$ and ITS of $0.43 \mathrm{MPa}$ ). It is postulated that

389 there may have been some cementitious material present in the recycled component. This is

390 possible as cores in the Figure 2 showed variability of the material found on the site, core 3 in the

391 figure clearly shows content of the cementitious material in the pavement layers.

392 When the results produced using the ITS and the ITSM are compared, it can be seen that there is much more variability in the ITSM data. If the particular case of Mix A in section 5 is omitted, it can be seen that the variability relative to the lab data is quite high, with stiffness values ranging from 50 to $99 \%$ of their lab-mixed counterparts. The situation is more consistent for ITS, with ITS values ranging from 87 to $100 \%$ of their lab-mixed counterparts. This would suggest that the ITS test is more robust and potentially better suited for assessing performance of site-mixed cold recycled materials.

\subsection{Follow-up Survey}

The final piece of information available on the perfomance of the material relates to the periodic 
section of the roads network was surveyed in March 2014 (4 months before the works) and again in March 2015 (8 months after the works). In this case the parameter of most interest is the central D1 (40) deflection - a measurement of how the pavement deflects when subjected to a typical wheel load of $40 \mathrm{kN}$. This deflection (expressed in microns) is an indicator of how well the upper layers of the pavement structure are performing, with lower values being more desireable. The results of this survey are shown below in Figure $\mathbf{1 0}$ and show a considerably improved performance, particularly in central section where the weaker subgrade is located. This road will be surveyed on an ongoing basis, but the results to date offer confidence that the cold-recycled materials can successfully be used to remediate issues associated with legacy roads.

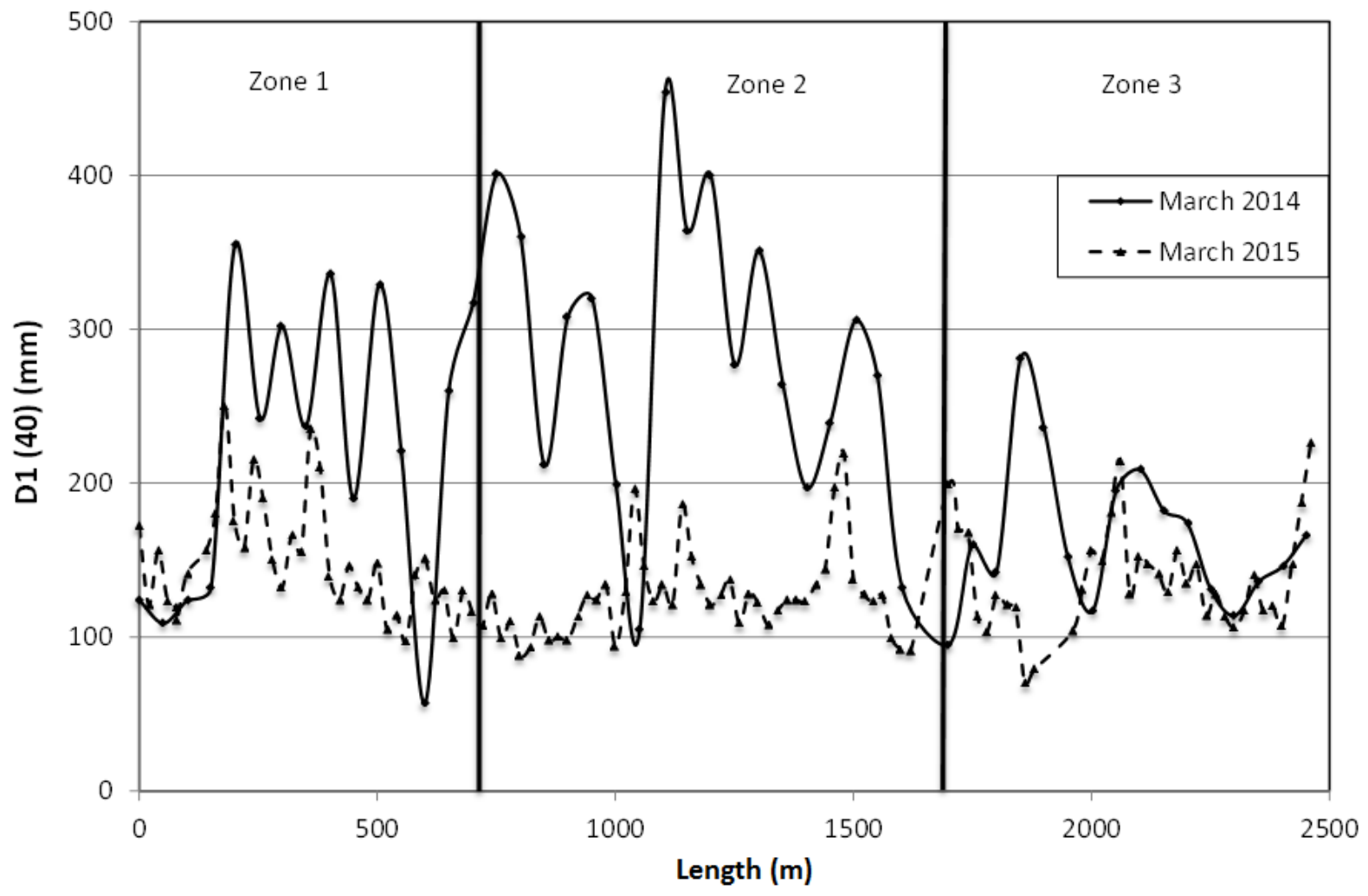

Figure 10. Results of FWD survey before and after the cold recycling scheme

\section{Discussion}

To date the biggest obstacle in applying cold recycling processes in road regeneration has been uncertainty about the material behaviour. This was further compounded by material evaluation 
procedures that were conservative and excessively long. The curing process in the material evaluation and mix design process was one of the biggest issues highlighted by industry $[8,14]$. This raised practical issues in the project procurement process, leading to delays in project time line and reluctance to specify the use of cold mix recycling as the preferred road rehabilitation process. The curing procedure specified by the NRA guidelines [15] requires curing of 28 days at $40^{\circ} \mathrm{C}$, irrespective of cement content in the mix. This is significantly longer than the times associated with traditional asphalt testing, where mix evaluation procedures take less than a week.

This study has shown that a modified specification with significantly reduced curing times is possible. Two curing streams have been adopted: 3 days at $50^{\circ} \mathrm{C}$ for mixes containing less than $1 \%$ cement, and 14 days at $20^{\circ} \mathrm{C}$ for mixtures containing more than $1 \%$ cement. Consequently, the mix performance can be evaluated employing standard asphalt mix evaluation test procedures for stiffness (as per EN 12697-26) and indirect tensile strength (as per EN 12697-23) The test results further showed that reduction in of the residual binder in the mix can be compensated by increase of the cement in the mix. This finding will help in reduction of cost of the mix production as the cost of the emulsion is high in comparison to the cost of the standard cement binder. This will lead to improved financial performance, and making the mix design and evaluation process more efficient will undoubtedly encourage greater usage of cold mix asphalt as a road rehabilitation procedure.

\section{Conclusions}

The results from this study have illustrated that cold mix recycling is a valuable rehabilitation process for legacy roads, where the material composition of the road is unknown. The study has shown that both cold recycling processes (emulsion and foam) can adequately improve the strength of the material so as to achieve an extended service life without the need for complete road regeneration. This leads to financial and environmental savings. 
- For legacy roads where the material variability can be high, it is important to obtain sufficient samples before site works commence. This shows the importance of preliminary investigations and gives confidence to subsequent mix designs.

- For the cold mix recycling procedures lower end of the IAN grading envelope [15] should be lowered in order to allow better curve fit and unnecessary inclusion of the fresh material.

\section{Acknowledgements}

The Authors would like to thank National Roads Authority of Ireland, Kilkenny County Council, Ireland and Pavement Management Services Ltd. for their support to the project. Authors would also like to thank Dr. Jan Valentin and Michael Engels for their help in planning and organising the laboratory testing programme. The work reported here was part of a project funded by the CEDR Transnational Road Research Programme Call 2012: Recycling: Road construction in a post-fossil fuel society that is being funded by Denmark, Finland, Germany, Ireland, Netherlands and Norway and managed by Nation Road authority, Ireland. 


\section{References}

463

464

465

466

467

468

469

470

471

472

473

474

475

476

477

478

479

480

481

482

483

484

485

486

487

488

489

490

491

492

493

494

495

496

497

498

499

500

501

502

1. (OECD), O.o.E.C.a.D., Road traffic, vehicles and networks. 2013 in Environment at a Glance 2013: OECD Indicators, OECD Publishing.

2. European Union Road Federation (ERF), European road statistics 2012. 2012: European Union Road Federation Publications.

3. (INDP), I.N.D.P., Transforming Ireland. 2007, Government of Ireland. p. 7.

4. (INDP), I.N.D.P., Economic and social infrastructure operational programme 2000-2006. 2000, Government of Ireland. p. 17 - 29.

5. (NRA), N.R.A., National Road Authority Annual Report 2004 and Programme for 2005. 2004, National Rods Authority, Dublin, Ireland.

6. Tabaković, A.G., A.; McNally, C. and Gilchrist, M.D., 2010, "The Influence of Recycled Asphalt Pavement on the Fatigue Performance of Asphalt Concrete Base Courses". ASCE Journal of Materials in Civil Engineering, Vol. 22, 6, pp. $643-650$., The influence of recycled asphalt pavement on the fatigue performance of asphalt concrete base courses. ASCE Journal of Materials in Civil Engineering, 2010. 22(6): p. 643 - 650.

7. (NRA), N.R.A., Series: 900; Road Pavements - Bituminous Bound Materials. 2011, National Rods Authority, Dublin, Ireland. : Specifications for Road Works.

8. Hogan, D.G., A.; Dillon, S. and Tabaković, A., Road Recycling in Ireland, in 11th Annual International Conference on Pavement Engineering and Infrastructure. 2012: John Moore University, Liverpool, UK.

9. Mulry, B.C., K. and Motherway, F., Cold in-situ recycling trial on the N15 National Primary Road, Sligo, Ireland, in The Journal of the Institute of Asphalt Technology. 2010, Asphalt Professional. p. 7.

10. Brennan, M.J.N., P.J.; Kavanagh, A. and Sheahan, J., The laboratory design process for cold recycled asphalt pavement, in The Journal of the Institute of Asphalt Technology,. 2011, Asphalt Professional. p. 7.

11. Valentin, J.S., J.; Formanová, Z.; Mollenhauer, K.; Engels, M.; Batista, F. and McNally, C., Introduction to European COREPASOL Project on Harmonizing Cold Recycling Pavement Techniques, in Transport Research Arena 2014. 2014: Paris, France.

12. Tabaković, A., Recycled Asphalt (RA) for Pavements, in Handbook of Recycled Concrete and Demolition Waste, F.T. Pacheco-Torgal, V.W.Y.; Labrincha, J.A.; Ding, Y. and de Brito, J., Editor. 2013, Woodhead Publishing. p. $394-419$.

13. Thanaya, I.N.A.Z., S. E. and Forth, J. P., A Laboratory Study on Cold-Mix, Cold-Lay Emulsion Mixtures. Institution of Civil Engineers, Transport, 2009. 162: p. 8.

14. Doyle, T.A.M., C.; Gibney, A. and Tabaković, A., Developing Maturity Methods for Assessment of Cold-mix Bituminous Materials. Construction and Building Materials, 2013. 38(1): p. 5.

15. (NRA), N.R.A., Interim Advice Note On Low Energy Pavements. 2011, National Roads Authority, Dublin, Ireland.: Specifications for Road Works.

16. Wirtgen, Cold Recycling Technology. 2010.

17. Doyle, T.G., A.; McNally, C. and Tabaković, A., Developing Specific Conditions for Cold-mix Pavement Materials, in Transport Research Arena Europe 2010. 2010: Brussels, Belgium. 
18. Niazi, Y.a.J., M, Effect of Portland Cement and Lime Additives on Properties of Cold In-Place Recycled Mixtures with Asphalt Emulsion. Construction and Building Materials, 2009. 23: p. 5.

19. Al-Busaltan, S.A.N., H; Atherton, W. and Sharples, G., Green Bituminous Asphalt Relevant for Highway and Airfield Pavements. Construction and Building Materials, 2012. 31: p. 7.

20. Al Nageim, H.A.-B., S.F.; Atherton, W. and Sharples, G., A comparative study for improving the mechanical properties of cold bituminous emulsion mixtures with cement and waste materials. Construction and Building Materials, 2012. 36: p. 5.

21. Choudhary, R.M., A. and Kaulgud, H.S. Use of Cold Mixtures for Rural Road Construction. in International Conference on Emerging Frontiers in Technology for Rural Area (EFITRA). 2012. International Journal of Computer Applications.

22. Merrill, D.N., M. and Carswell, I., A Guide to the Use and Specification of Cold Recycled Materials for the Maintenance of Road Pavements. 2004.

23. Muthen, K.M., Foamed asphalt mixes-mix design procedure. 1998, Sabita Ltd and CSIR Transportek, South Africa.

24. (PRA), P.R.A., Specifications for Construction, CETO-EP. 2009.

25. (SRA), S.R.A., General Specifications for Maintenance, PG-4 - Art.s 20 \& 21. 2009.

26. Kim, Y.a.L., H.D., Development of Mix Design Procedure for Cold In-Place Recycling with Foamed Asphalt. Materials in Civil Engineering, 2006. 18(1): p. 8.

27. Leech, D., Cold Bituminous Materials for Use in the Structural Layers of Roads. 1994. 